\title{
ANALISIS KETEBALAN DAN KOMPOSISI PADA KONSTRUKSI SOIL SEMEN \\ (Studi Kasus : PT ELEVASI SAGARMATHA - MERAUKE)
}

\author{
St. Maryam $\mathrm{H}^{1}$, Lambang Basri Said ${ }^{2}$, Burhanuddin yasin ${ }^{3}$ \\ ${ }^{1}$ Dosen Magister Teknik Sipil PPS-UMI Makassar. \\ Jl. Urip Sumoharjo No. 225 Makassar, Telp.454534 \\ ${ }^{2}$ Dosen Magister Teknik Sipil PPS-UMI Makassar. \\ Jl. Urip Sumoharjo No. 225 Makassar, Telp.454534 \\ ${ }^{3}$ Karyawan PT. Elevasi Sagarmatha \\ Jl. Buakana no.30 Makassar telp. 08124820225, email : \\ burhanuddinyasin2568@gmail.com
}

\begin{abstract}
ABSTRAK
Konstruksi soil cement mempunyai peranan penting dalam mengatasi tidak adanya material agregat seperti batu dan pasir diwilayah Merauke atau sebagian besar wilayah bagian selatan Papua.Jenis konstruksi ini banyak diterapkan dibidang transportasi, baik untuk perkerasaan jalan maupun untuk konstruksi runway bandara serta apron. Soilcement dalam lapisan konstruksi banyak dipakai sebagai lapisan pondasi bawah (LPB) atau bahkan untuk lapis pondasi atas (LPA). Posisi pada lapisan perkerasan tergantung pada nilai CBR dan komposisi bahan pencampurannya atau kadar semen portland yang diberikan. Tujuan penelitian ini adalah untuk menganalisa penerapan soilcemen pada bandara terkait dengan nilai daya dukung yang dipersyaratkan untuk masing-masing lapisan perkerasan serta persentase komposisi bahan tambah yang tepat agar memperoleh nilai CBR yang memenuhi spesifikasi teknik bandara. Data yang dikumpulkan dalam penelitian ini terdiri dari informasi langsung dari pihak operator bandara, data penelitian laboratorium mekanika tanah dinas Pekerjaan Umum bidang Bina Marga kabupaten Merauke. Hasil analisis menggambarkan komposisi semen portland 12\%, 21\% dan nilai CBR yang diperoleh untuk semen porland 12\% adalah CBR 98\%, untuk semen porland $21 \%$ adalah CBR $115 \%$ serta rencana ketebalan lapisan yang dilaksanakan dilapangan $50 \mathrm{~cm}$ untuk semen porland $12 \%$ dan $30 \mathrm{~cm}$ untuk semen porland $21 \%$. Metode penelitian yang digunakan adalah metode trial eror dan metode CBR dengan nilai CBR 82\% untuk komposisi $12 \%$ dan $101 \%$ untuk komposisi $21 \%$.
\end{abstract}

Kata Kunci : Komposisi Semen Portland, Nilai CBR.

\section{PENDAHULUAN}

Penerapan konstruksi soilcement telah cukup Luas di praktikkan di Indonesia khususnya di Kalimantan dan di Papua termasuk sebagian di pulau Sumatera. Di Papua khususnya di Papua bagian Selatan dimana secara topografi, daerah ini terdiri dari dataran rendah dan datar yang banyak terdapat rawa-rawa serta lahan gambut..Sehingga hampir tidak tersedia batu maupun pasir yang layak untuk material konstruksi. Wilayah ini 90\% adalah terdiri dari tanah lempung, Kondisi seperti inilah yang membuat pihak PU atau Pemerintah setempat memakai soilcement sebagai solusi dalam hal perkerasan jalan maupun bandara, bahkan bandara Mopah di Kabupaten 
Merauke yang hampir seluruh Runwaynya menggunakan soilcement dengan Panjang $2500 \mathrm{M}$ dan lebar $45 \mathrm{M}$. Begitupun sebagian luas Apron memakai konstruksi soilcement dengan tebal $80 \mathrm{~cm}$.

Seiring waktu dan kemajuan ilmu pengetahuan khususnya dibidang konstruksi jalan, termasuk perkembangan volume dan jenis kendaraan yang melintas Sehingga membuat kerusakan jalan yang memakai konstruksi soilcement. Baik di jalan utama maupun jalan Propinsi masih cukup banyak ruas jalan yang rusak parah dan sangat sulit dilalui kendaraan lagi dimusim hujan, tentu hal ini terjadi disamping faktor alam namun yang lebih penting untuk diteliti adalah faktor perencanaan maupun pengawasan pelaksanaan dilapangan,termasuk juga pemilihan jenis konstruksi perkerasaan yang tepat. Melihat dan merasakan kondisi tersebut diatas yang cukup memprihatinkan. Maka perlu solusi secara teknis agar kerusakan tersebut bisa diatasi oleh pemerintah atau pengambil kebijakan. Bila perlu mengkaji kembali jenis konstruksi yang tepat sesuai kondisi daerah dan ketersediaan material pada daerah tersebut, khusus untuk jenis konstruksi perkerasaan soilcemet perlu ditinjau kembali kelayakannya pada perkerasaan jalan yaitu lebih mengkaji kelemahan-kelemahan konstruksi jenis ini dan posisinya pada lapisan perkerasaan serta mutu seperti apa yang harus dipenuhi, tebal yang cukup dan ideal serta teruji di lapangan. Hal ini sangat penting untuk diteliti agar ke depannya semakin sedikit terjadi kerusakan jalan yang parah sebelum umur rencana jalan, sehingga tidak merugikan masyarakt umum dan mengganggu distribusi barang dan orang yang tentu akan berdampak kepada nilai cost atau biaya angkutan yang akan mengganggu perekonomian dan Kenyamanan berlalu lintas masyarakat.

Persoalan seperti yang kami kemukakan di atas adalah kenyataan yang mendasari Subjek untuk membuat penelitian agar soilcement sebagai konstruksi alternative dari keterbatasan bahan material batu dan pasir dapat menjadi solusi yang layak diterapkan pada jalan, baik dari sisi biaya yang ekonomis maupun dari mutu konstruksi yang baik dan sesuai umur rencana agar tidak terjadi lagi pekerjaan perbaikan yang berulangulang setiap tahun dilokasi yang sama. Di Papua khususnya jarak dari satu Kabupaten ke Kabupaten lain cukup jauh dan melewati banyak sungai dan rawa yang tentu mempunyai tantangan tersendiri dilapangan. Kondisi seperti inilah yang menurut kita untuk melakukan inovasi-inovasi dibidang konstruksi jalan dengan memanfaatkan material yang tersedia dilapangan agar perhubungan darat dapat lancar dan terkoneksi secara luas bisa menjawab permasalahan ekonomi social maupun politis bahkan keamanan demi keadilan dan kesejahteraan social demi keutuhan NKRI.

\section{METODE PENELITIAN}

Dari hasil pengumpulan dara primer dan sekunder, yang diperoleh dilapangan dan diolah, maka metode penelitain yang digunakan adalah metode trial dan metode CBR.

1. Mutu pelaksanaan

Untuk mencapai mutu pelaksanaan yang direncanakan harus melalui tahapan tahapan yang sesuai mekanisme teknik yaitu :

a. Menentukan jenis yang akan distabilisasi.

b. Jenis struktur atau lapisan perkerasan yang akan distabilisasi.

c. Ketentuan-ketentuan soilcemen yang akan dicapai (CBR).

d. Memperhatikan waktu ikat semen

e. Komposisi air yang tepat.

f. Proses pemadatan yang tepat

g. Pemeliharaan konstruksi dilapangan. 
1. Menentukan komposisi

Komposisi semen ditentukan melalui metode trial eror sampai diperoleh nilai CBR yang diinginkan.

2. Tebal perkerasaan

Pada pekerjaan ini tebal perkerasan sudah di tentukan oleh pihak direktorat teknik bandara berdasarkan nilai PCN yang ditentukan. Makin tebal perkerasan dari lapisan konstruksi makin tinggi nilai PCN yang dicapai

\section{HASIL DAN PEMBAHASAN}

1. Karakteristik Tanah

Pengujian tanah dilakukan untuk mengetahui sifat - sifat fisik atau karakteristik tanah pada bandara Mopah Merauke. Pengujian yang dilakukan adalah, analisa saringan material Selmat, Kompaksi, Liquid Limit, Plastis Limit dan CBR Laboratorium. Hasil pengujian tersebut dirangkum pada tabel 4.1

Tabel 4.1. Hasil Tes Pengujian Karakteristik Tanah Dasar

\begin{tabular}{|c|c|c|c|c|}
\hline & \multirow{2}{*}{ Uraian } & \multicolumn{3}{|c|}{ SUMMARY } \\
\hline & & & Benda Uji & Ket \\
\hline \multirow{9}{*}{ 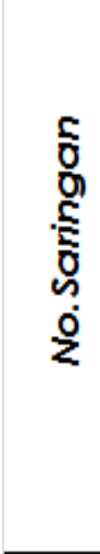 } & $\# 20$ & & 68.67 & \\
\hline & $\# 30$ & & 62.11 & \\
\hline & $\# 40$ & & 57.97 & \\
\hline & $\# 50$ & & 52.92 & \\
\hline & $\# 60$ & & 52.35 & \\
\hline & $\# 80$ & & 41.34 & \\
\hline & $\# 100$ & & 15.97 & \\
\hline & $\# 200$ & & 0.54 & \\
\hline & Pan & & 0.00 & \\
\hline \multicolumn{5}{|c|}{ Pemadatan } \\
\hline \multicolumn{2}{|c|}{ Berat Jenis } & & 2.649 & \\
\hline \multicolumn{2}{|c|}{$\gamma D \operatorname{Max}$} & & $1.745 \%$ & \\
\hline \multicolumn{2}{|c|}{ W Optimum } & & $10.38 \%$ & \\
\hline \multicolumn{5}{|c|}{ ATTEMBERG } \\
\hline \multicolumn{2}{|c|}{ Liquid Limit } & & \multirow{3}{*}{ Non Plastis } & \\
\hline \multicolumn{2}{|c|}{ Plastic Limit } & & & \\
\hline \multicolumn{4}{|c|}{ Indek Plastisitas ( SNI 1966 : 2008 ) } & \\
\hline \multirow{2}{*}{\multicolumn{2}{|c|}{ CBR Rendaman ( SNI $1744: 2012$ ) }} & $0.1^{11}$ & $10.75 \%$ & \multirow{2}{*}{ Min $6 \%$} \\
\hline & & $0.2^{\prime \prime}$ & $11.73 \%$ & \\
\hline
\end{tabular}

Berdasarkan hasil pengujian karakteristik tanah dasar, maka didapat hasil CBR adalah $10.75 \%$. dan nilai CBR ini memenuhi standart spesifikasi Direktorat Jendral Bandar Udara. 
2. Analisa Soil Semen

Soil Semen adalah campuran antara tanah dan semen sebagai bahan pengikat atau bahan tambah.. Pada penelitian ini kami melakukan uji penambahan dengan metode percobaan trial error, dilakukan beberapa penambahan komposisi semen pada tanah, dan hasil trial mix penambahan $12 \%$ semen di dapat hasil CBR 82\% dengan demikian memenuhi standart spesifikasi Direktorat Bandar Udara untuk komposisi pada lapisan pondasi bawah setebal $50 \mathrm{~cm}$ dengan hasil CBR minimum $25 \%$. Hasil tes trial eror dapat dilihat pada tabel dibawah ini :

Tabel 4.2 Trial Eror Prosentase Penambahan Semen

3. Desai

\begin{tabular}{|l|l|l|l|l|l|}
\hline No & $\begin{array}{l}\text { Prosentase } \\
\text { penambahan } \\
\text { Semen }\end{array}$ & $\begin{array}{l}\text { Kadar air } \\
\text { optimum }\end{array}$ & $\begin{array}{l}\text { yd } \\
\text { max }\end{array}$ & $\begin{array}{l}\text { fd } \\
\mathbf{9 5 \%}\end{array}$ & $\begin{array}{l}\text { CBR } \\
(\%)\end{array}$ \\
\hline 1 & Tanah+Semen 6\% & 8.5 & 1.81 & 1.72 & 43 \\
\hline 2 & $\begin{array}{l}\text { Tanah +Semen } 8 \% \\
\text { Tanah + Semen } \\
10 \%\end{array}$ & 7.5 & 1.8 & 1.71 & 46 \\
\hline 3 & $\begin{array}{l}\text { Tanah + Semen } \\
12 \%\end{array}$ & 7.2 & 1.83 & 1.73 & 49 \\
\hline 4 & $\begin{array}{l}\text { Tanah + Semen } \\
21 \%\end{array}$ & 7.3 & 1.84 & 1.75 & 82 \\
\hline 5
\end{tabular}

$\mathrm{n}$

Pelak

sanaa

$\mathrm{n}$

Dilap

angan

Berdasarkan hasil trial eror dilaboratorium, maka ditentukan bahwa Soil + Semen dengan prosentase 12\% digunakan pada lapis kedua setelah Subgrade dengan ketebalan $50 \mathrm{~cm}$ dan pelaksanaan penghamparannya dilakukan dengan dua layer. Kemudian untuk tanah dengan penambahan prosentase semen sebanyak $21 \%$ digunakan pada lapisan ke 3 dengan ketebalan $30 \mathrm{~cm}$.

4. Langkah - Langkah Pelaksanaan dilapangan

a. Subgrade

Pada penyiapan tanah dasar, setelah ditentukan elevasi dan dimensi seperti ditunjuk dalam gambar rencana, maka dilakukan pembersihan dan pemadatan sesuai dengan hasil kompaksi dilaboratorium. Kemudian di tes kepadatannya untuk memenuhi standart minimum $6 \%$ seperti yang tertulis di spesifikasi

b. Layer ke Dua

Pada lapisan layer ke dua, standart spesifikasi yang ditetapkan adalah CBR $25 \%$. Dengan ketebalan $50 \mathrm{~cm}$, dan dihampar layer per layer, untuk satu layer, ketebalan yang disarankan adalah $20 \mathrm{~cm}$, kemudian dipadatkan dan di hampar layer selanjutnya.pada layer ke dua ini menggunakan material Soil + Semen $12 \%$. Metode penghamparan semen pada layer ke dua ini adalah berdasarkan berat kering tanah dalam $1 \mathrm{~m} 3$. Sehingga membutuhkan semen sebanyak $180 \mathrm{~kg}$. pada layer ke dua ini pelaksanaannya adalah, setelah dipadatkan tanah dengan ketebalan $20 \mathrm{~cm}$, kemudian digemburkan kembali 
dan dihampar semen sesuai dengan hitungan tiap $1 \mathrm{~m} 3$. Begitu seterusnya hingga mencapai ketinggian elevasi sesuai dalam gambar rencana. Setelah ketinggian hamparan mencapai elevasi rencana dan kepadatan sudah memenuhi standart, dilakukan pengujian DCP dan Sandcone. Hasil pengujian DCP dan Sandcone dapat dilihat pada tabel 4.3 dan 4.4

Tabel 4.3.

Rekapitulasi hasil tes DCP dan Sandcone dilapangan pada tanah + Semen 12\%

\begin{tabular}{|c|c|c|c|}
\hline No. Titik & $\mathbf{R} / \mathbf{L}$ & $\begin{array}{l}\text { DCP } \\
(\%) \\
\end{array}$ & $\begin{array}{l}\text { SANDCONE } \\
(\%)\end{array}$ \\
\hline $1+700$ & $\mathrm{R}$ & 108.93 & 100.55 \\
\hline $1+500$ & $\mathrm{R}$ & 89.64 & 99.66 \\
\hline $1+300$ & $\mathrm{R}$ & 87.86 & 100.51 \\
\hline $1+100$ & $\mathrm{R}$ & 77.29 & 100.14 \\
\hline $0+500$ & $\mathrm{~L}$ & 95.18 & 99.8 \\
\hline $0+700$ & $\mathrm{~L}$ & 122.72 & 100.42 \\
\hline $0+900$ & $\mathrm{~L}$ & 102.4 & 100.26 \\
\hline $1+100$ & $\mathrm{~L}$ & 100.73 & 100.2 \\
\hline $1+300$ & $\mathrm{~L}$ & 102.7 & 100.04 \\
\hline $0+1500$ & $\mathrm{~L}$ & 76.34 & 99.63 \\
\hline $1+700$ & $\mathrm{~L}$ & 106.34 & 99.81 \\
\hline $0+010$ & $\mathrm{~L}$ & 93.51 & 100.05 \\
\hline $0+300$ & $\mathrm{~L}$ & 87.73 & 100.38 \\
\hline $0+700$ & $\mathrm{R}$ & 105.2 & 99.87 \\
\hline $0+900$ & $\mathrm{R}$ & 99.81 & 99.78 \\
\hline $0+500$ & $\mathrm{R}$ & 100.87 & 100.2 \\
\hline $0+300$ & $\mathrm{R}$ & 116.96 & 100.35 \\
\hline $0+010$ & $\mathrm{R}$ & 89.91 & 99.93 \\
\hline \multicolumn{2}{|c|}{ Rata - Rata } & 98.007 & 100.09 \\
\hline
\end{tabular}

Berdasarkan hasil tes DCP dan Sandcone dilapangan, penghamparan Semen pada tanah dengan prosentase $12 \%$, kepadatannya mencapai sesuai dengan standart Spesifikasi yang direncanakan.

c. Layer ke tiga

Pada layer ke tiga ini menggunakan material Soil + Semen dengan prosentase $21 \%$ terhadap berat tanah kering dengan ketebalan $30 \mathrm{~cm}$.metode pelaksanaannya dilakukan dua layer. Pada layer pertama ketebalan mencapai $15 \mathrm{~cm}$, kemudian dihampar semen seperti pada pelaksanaan layer ke 2. Begitu seterusnya hingga mencapai elevasi rencana. Setelah kepadatan secara visual sudah sesuai, maka dilakukan tes DCP dan Sandcone.

Tabel 4.4. Hasil Tes DCP dan Sandcone Soil+ Semen 21\%

\begin{tabular}{|l|l|l|l|}
\hline No. Titik & R/L & $\begin{array}{l}\text { DCP } \\
(\%)\end{array}$ & $\begin{array}{l}\text { SANDCONE } \\
(\%)\end{array}$ \\
\hline $1+750$ & R & 139.96 & 99.92 \\
\hline
\end{tabular}




\begin{tabular}{|c|c|c|c|}
\hline $1+550$ & $\mathrm{R}$ & 93 & 100.15 \\
\hline $1+350$ & $\mathrm{R}$ & 131 & 98.45 \\
\hline $1+150$ & $\mathrm{R}$ & 113.12 & 100.4 \\
\hline $0+550$ & $\mathrm{~L}$ & 124.84 & 101.89 \\
\hline $0+750$ & $\mathrm{~L}$ & 140.2 & 99.68 \\
\hline $0+950$ & $\mathrm{~L}$ & 100.88 & 99.86 \\
\hline $1+150$ & $\mathrm{~L}$ & 122.1 & 100.44 \\
\hline $1+350$ & $\mathrm{~L}$ & 110.94 & 101.4 \\
\hline $1+550$ & $\mathrm{~L}$ & 101.89 & 100.48 \\
\hline $1+750$ & $\mathrm{~L}$ & 112.25 & 103.91 \\
\hline $0+010$ & $\mathrm{~L}$ & 108.98 & 100.48 \\
\hline $0+350$ & $\mathrm{~L}$ & 110.2 & 98.73 \\
\hline $0+750$ & $\mathrm{R}$ & 110.47 & 100.18 \\
\hline $0+950$ & $\mathrm{R}$ & 112.25 & 101.72 \\
\hline $0+550$ & $\mathrm{R}$ & 116.77 & 102.04 \\
\hline $0+350$ & $\mathrm{R}$ & 113.12 & 99.98 \\
\hline $0+010$ & $\mathrm{R}$ & 108.09 & 102.44 \\
\hline \multicolumn{2}{|c|}{ Rata - Rata } & 115.003 & 100.68 \\
\hline
\end{tabular}

\section{A. Kesimpulan}

\section{PENUTUP}

Berdasarkan hasil analisis data, dapat diperoleh kesimpulan sebagai berikut :

1. Pengujian karakteristik tanah Selmat pada bandara Mopah Merauke, memiliki hasil tes Dry density $1.745 \%$, kadar air optimum $10.38 \%$, CBR $10.75 \%$

2. Pengujian Trial eror untuk analisa Soil + Semen, didapat hasil yang memenuhi syarat minimum CBR. Yaitu penambahan Semen 12\% dan 21\% terhadap berat kering tanah selmat

3. Hasil tes DCP dilapangan untuk material Soil + Semen $12 \%$ rata - rata mencapai $98.007 \%$ lebih tinggi dari syarat ketentuan Direktorat Jendral Bandar Udara yaitu $80 \%$

4. Hasil tes DCP dilapangan untuk material Soil + Semen $21 \%$ rata - rata mencapai $115.003 \%$ lebih tinggi dari syarat ketentuan Direktorat Jendral Bandar Udara yaitu $100 \%$

5. Berdasarkan hasil uji DCP dan Sandcone dilapangan untuk Soil + Semen $12 \%$ dan Soil + Semen 21\%, didapat hasil bahwa material yang menggunakan Soil + Semen dengan jenis tanah selmat tertentu serta komposisi yang sesuai hasil pengujian di Laboratorium maupun di Lapangan dapat memenuhi standart Spesifikasi Direktorat Bandar Udara sehingga layak digunakan untuk kegiatan penerbangan dengan jenis Pesawat berbadan Lebar seperti jenis pesawat Boeing seri 800 .

\section{B. Saran}

Berdasarkan hasil penelitian, diusulkan beberapa saran sebagai berikut: 
1. Perlu dilakukan pengkajian ulang, terhadap fungsi dan kelayakan runway bandara Mopah Merauke. Apakah dengan hasil tes yang ada dapat didarati pesawat berbadan lebar dan beratnya lebih dari design rencana

2. Material Soil + Semen apakah layak direkomendasikan untuk base pekerjaan jalan raya

\section{Daftar Pustaka}

Adha. I., (2009) Pengaruh Resapan Air (Water Adsorption) Terhadap Daya Dukung Lapis Pondasi Tanah Semen (Soil Cement Base), Jurnal Rekayasa Vol.13. No 1.Jurusan Teknik Sipil Universitas Lampung: Bandar Lampung.

Asyianto., (2008) Metode Konstruksi Proyek Jalan, Penerbit Universitas Indonesia: Jakarta

Departement Of Defense, (2004), Pavement Maintenance Management, Ufc 3-270-08, Unified Facilities Criteria (Ufc), Usa

Hamiran, S. (2004) Konstruksi Jalan Raya : Nova: Bandung.

Hardiyatmo, H.C.,(2007) Pemeliharaan Teknik Jalan Raya, Poleteknik Negeri Bandung: Bandung.

Herman., Edward J,. (2014) Pengaruh Variasi Semen Terhadap Nilai CBR Base Perkerasan Lentur Tipe Cement Treated Bae (CTB). Jurnal Rekayasa Sipil. Vol 10 No, 2 Oktober 2014: Padang

Kezdi, A., (1979), Stabilizet Earth Road, Elsvier Scientific Publising Company, Neyyork.

Natoonis F., Candra I, (1998), Penggunaan Campuran Tanah Asal Dengan Semen Kupang Sebagai Material Pondasi Jalan Dikupang (Ntt), Skripsi S1 Teknik Sipil Universitas Kristen Petra, : Surabaya

Rudi,W,. Waluwo,N,.Lendra,.(2008) studi perbandingan biaya konstruksi perkerasan kaku dan perkerasan lentur. Jurnal teknik sipil vol 9 no. 1, jurusan teknik sipil fakultas universitas palangka raya : diponegoro semarang. 
Silvia, S. (1995) Perkerasan Lentur Jalan Raya, Penerbit Nova : Bandung.

Suryawan, A. (2009) Perkerasan Jalan Beton Sement Porlant : Beta Offset : Jogyakarta.

Sukirman. Silvia. 2003. Beton Aspal Campuran Panas, Edisi Kedua. Yayasan Obor Indonesia. Jakarta. 